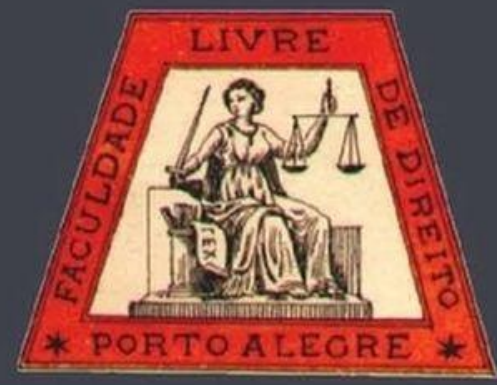

\title{
A problemática do tráfico de mulheres para fins de exploração sexual: uma análise comparativa entre Moçambique e outros países da SADC
}

The issue of trafficking in women for the purpose of sexual exploitation: a comparative analysis between Mozambique and other SADC countries

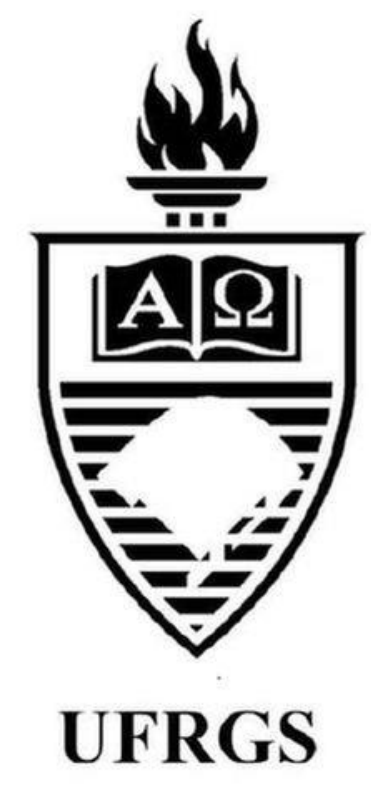

\author{
José Joaquim Franze \\ Universidade do Zimbabwe
}

Joaquim Miranda Maloa

Universidade Eduardo Mondlane 


\title{
A problemática do tráfico de mulheres para fins de exploração sexual: uma análise comparativa entre Moçambique e outros países da SADC
}

\author{
The issue of trafficking in women for the purpose of sexual exploitation: a comparative analysis \\ between Mozambique and other SADC countries
}

José Joaquim Franze*

Joaquim Miranda Maloa**

\begin{abstract}
REFERÊNCIA
FRANZE, José Joaquim; MALOA, Joaquim Miranda. A problemática do tráfico de mulheres para fins de exploração sexual: Uma análise comparativa entre Moçambique e outros países da SADC. Revista da Faculdade de Direito da UFRGS, Porto Alegre, n. 39, vol. esp., p. 112-128, dez. 2018.
\end{abstract}

\section{RESUMO}

Através do método comparativo, este artigo aborda o tráfico de mulheres para fins de exploração sexual, a partir de uma perspectiva comparativa entre Moçambique e outros países da Comunidade para o Desenvolvimento da África Austral (SADC), bem como o seu enquadramento legal. A Partir da revisão bibliográfica, reportagens jornalísticas e entrevistas com atores significativos do cotidiano moçambicano, constatou-se que o tráfico de mulheres para fins de exploração sexual, constitui uma realidade inegável, pois, muitas mulheres são traficadas com promessa de uma vida melhor em grandes centros urbanos. No caso de Moçambique, essas mulheres saem das suas áreas residenciais, principalmente no interior, com a esperança de uma integração social através de trabalho remunerável e acabam caindo nas mãos de traficantes, tornando-se escravas sexuais a favor de terceiros. Muitos desses casos terminam pela sua infeção por doenças de transmissão sexual, resultando em mortes. Também-se observou que tanto em Moçambique como em outros países da SADC, esta realidade ocorre devido a exclusão socioeconômica de muitas famílias que veem no convite de trabalho a oportunidade de melhorar a sua condição de vida.

PALAVRAS-CHAVE

Tráfico de mulheres. Exploração sexual. HIV-Aids. SADC.

\section{ABSTRACT}

Through the comparative method, this article addresses trafficking in women for purposes of sexual exploitation from a comparative perspective between Mozambique and other Southern African Development Community (SADC) countries, as well as their legal framework. From the bibliographical review, journalistic reports and interviews with significant actors in Mozambican daily life, it was found that the trafficking of women for the purpose of sexual exploitation is an undeniable reality, since many women are trafficked with a promise of a better life in large centers urban In the case of Mozambique, these women leave their residential areas, mainly in the interior, in the hope of a social integration through paid work and end up falling into the hands of traffickers, becoming sexual slaves in favor of third parties. Many of these cases end up with their infection from sexually transmitted diseases, resulting in deaths. It was also observed that in Mozambique and in other SADC countries, this reality occurs due to the socioeconomic exclusion of many families that see in the work invitation the opportunity to improve their living conditions.

\section{KEYWORDS}

Trafficking of women. Sexual exploitation. HIV-Aids. $S A D C$.

\section{SUMÁRIO}

Introdução. 1. Análise comparativa de tráfico de mulheres para fins de exploração sexual na SADC. 1.1 Contexto geral de tráfico de mulheres para fins de exploração sexual na SADC. 1.2 Quadros Jurídico-legais Nacionais sobre o Tráfico de Mulheres nos Estados-Membros da SADC. 1.3 O cenário do Tráfico de Mulher em Moçambique e África do Sul. 1.3.1 Moçambique. 1.3.2 África do Sul. Conclusão. Referências.

\footnotetext{
* Mestre pela Universidade do Zimbabwe.

${ }^{* *}$ Pesquisador do Centro de Pesquisa e Promoção Social, Moçambique. Doutor em sociologia pela USP, mestre pela mesma Universidade e graduado em sociologia pela universidade Eduardo Modlane em Moçambique.
} 


\section{INTRODUÇÃO}

Este artigo aborda o tráfico de mulheres para fins de exploração sexual a partir de uma perspectiva comparativa entre Moçambique e outros países da Comunidade para o Desenvolvimento da África Austral-SADC (Angola; África do Sul; Botswana; República Democrática do Congo; Lesoto; Madagascar; Malawi; Maurícia; Moçambique; Namíbia; Seychelles; Suazilândia; Tanzânia; Zâmbia e Zimbabwe), bem como o seu enquadramento legal. O crime de tráfico de mulheres é definido pela Convenção das Nações Unidas Contra o Crime Organizado Transnacional ${ }^{1}$ "Convenção de Palermo" (1998 $\left.\$ 3^{\circ}\right)$, como tráfico de pessoas, consistindo em: recrutamento, transporte, transferência, alojamento ou acolhimento de pessoas, recorrendo à ameaça ou ao uso da força ou a outras formas de coação, ao rapto, à fraude, ao engano, ao abuso de autoridade ou de situação de vulnerabilidade ou à entrega ou aceitação de pagamentos ou beneficios para obter o consentimento de uma pessoa que tem autoridade sobre outra, para fins de exploração. Segundo a convenção, a referida exploração deverá incluir, pelo menos, a exploração da prostituição de outrem ou outras formas de exploração sexual, o trabalho ou serviços forçados, a escravatura ou práticas similares à escravatura, a servidão ou a extração de órgãos.

Para compreendermos as atuais tendências, causas, efeitos e impactos do crime do tráfico de mulheres na reigião da África Austral (SADC), recorremos ao método comparativo, como defendem Schneider e Schmitt (1994). Este método permite cobrir regularidades, perceber deslocamentos e transformações, construir modelos e tipologias, identificar continuidades e descontinuidades, semelhanças e diferenças, explicitando as determinações mais gerais que regem os fenômenos sociais.

A SADC, atualmente conta com 15 países membros, com aspectos adversos e caracterizados por uma diversidade nas riquezas naturais, nas prioridades do seu desenvolvimento, nas estruturas de produção, nos padrões de comércio, na alocação de recursos e nas afiliações internacionais (MURAPA, 2002; CHICHAVA, 2007).

À exceção da África do Sul, as restantes economias dos países membros da SADC, tomadas individualmente são tão pequenas e têm um papel periférico na economia mundial. É dentro deste contexto que os países procuram atrair investimentos através de projetos regionais. Pelo que, a distribuição dos pelouros foi a seguinte: Angola - para área de energia; Botswana - doenças de gado e sementes; Lesotho - utilização e conservação dos solos; Malawi florestas e fauna; Moçambique - transportes e comunicações; Namíbia - pesca; Swazilândia treino e formação do pessoal; Tanzânia industrialização; Zâmbia - fundo de desenvolvimento e recursos mineiros; Zimbabwe - a agricultura e segurança alimentar. Neste caso, cada país é responsável por todos os projetos do setor que lhe está distribuído, tendo para isso, sido constituído as chamadas Unidades Técnicas de Apoio (UTA), com a presença de técnicos nacionais e de outros países. A única estrutura central permanente era o Secretariado Executivo, que funcionava em Gabarone, tendo por funções a preparação de reuniões (PEREIRA, 1995).

As economias da SADC têm registrado elevadas taxas de crescimento, acelerando seu crescimento em média anual de $3.2 \%$, não obstante o abrandamento de crescimento experimentado noutras regiões do continente. A

\footnotetext{
${ }^{1}$ Disponível em: <http://sinus.org.br/2014/wpcontent/uploads/2013/11/OIT-Protocolo-de-Palermo.pdf $>$. Acesso em 05 de agosto 2017.
} 
melhoria no crescimento do PIB nas economias da SADC é enxergado como algo que fica a dever-se, entre outros factores, ao recente clima de paz e estabilidade política, ao crescimento da indústria extractiva dos recursos naturais (petróleo no caso de Angola, Diamante no caso da República Democrática do Congo e África do Sul) e a melhoria da gestão das políticas macroeconômicas na maioria dos países membros da SADC (SADC, 2013).

\section{ANÁLISE COMPARATIVA DE TRÁFICO DE MULHERES PARA FINS DE EXPLORAÇÃO SEXUAL NA SADC}

A análise comparativa aqui apresentada, tornou-se possível através de informações baseadas em reportagens jornalísticas, pesquisa bibliográfica e entrevistas com atores significativos do cotidiano moçambicano, seguindo três princípios, sendo que: o mais geral, incidiu-se sobre o tráfico de mulheres para fins de exploração sexual na SADC; o outro debruçou-se sobre o tratamento legal e por último, o específico, que debruçou-se sobre a comparação dos cenários de tráfico de mulheres para fins de exploração sexual na África do Sul e Moçambique. Escolheu-se esses países, primeiro por causa da proximidade geográfica; segundo, porque a economia urbana moçambicana depende da África do Sul e terceiro, pelo fato de que grande parte do tráfico de mulheres moçambicanas ocorre naquele país. Nesta análise comparativa, utilizamos poucos dados estatísticos, isto porque, segundo Observatório ACP das Migrações (2011), é difícil recolher dados exatos sobre o tráfico de pessoas, em virtude do carácter clandestino do fenômeno. Os dados disponíveis não permitem uma descrição adequada das tendências e podem, paralelamente, sobrestimar ou subestimar a verdadeira dimensão do fenômeno, devido à deficiências metodológicas ou a uma representatividade insuficiente. Além disso, as vítimas do tráfico não denunciam por vergonha ou por receio de represálias por parte dos traficantes.

\subsection{Contexto geral de tráfico de mulheres para fins de exploração sexual na SADC}

Tanto em Moçambique como em outros países da SADC passam por problemas do tráfico internacional de mulheres para fins de exploração sexual, como podemos inferir do estudo de Shelley (2010), apontando que as mulheres e raparigas constituem grupos de pessoas mais vulneráveis ao tráfico de pessoas, estando em larga medida, sujeitas à exploração sexual, à exploração laboral e ao trabalho forçado.

As mulheres são a camada mais vulnerável, devido a sua baixa condição social e econômica. Os outros grupos vulneráveis incluem crianças, pessoas portadoras de deficiência, pessoas com albinismo e pessoas deslocadas. Todavia, qualquer um, pode ser uma vítima do crime de tráfico de pessoas, dependendo da demanda que os traficantes tencionarem satisfazer. Em muitos casos, são vítimas vulneráveis ao tráfico de pessoas, indivíduos mais desfavorecidos, com destaque para os desempregados e as crianças órfãs. A exploração sexual ocorre também no contexto de casamentos forçados e do uso de vítimas como escravas sexuais (UNICEF, 2005).

Há consenso nas fontes de pesquisas sobre tráfico de mulheres (SERRA, s/d; UNESCO, 2006; RODRIGUES, 2012; UNICEF, 2005), segundo o qual, o principal móbil do tráfico de mulheres se circunscreve na: a) Pobreza ou vulnerabilidade sócio econômica das vítimas, no sentido de que as pessoas nesta situação, facilmente se submetem as propostas de uma vida melhor sem questionar a veracidade das mesmas, simplesmente buscam satisfazer as suas necessidades de sobrevivência em razão da ausência de uma perspectiva de um futuro risonho; b) Demanda pela exploração sexual de mulheres, dado aos extraordinários lucros que atividade representa aos elementos da rede de 
traficantes; c) Instabilidade política, econômica e civil em regiões de conflito, no sentido de que as pessoas em particular as mulheres são obrigadas pela situação a aceitar qualquer proposta desde que consiga alcançar o seu único objetivo que é a sua sobrevivência; d) Corrupção de funcionários públicos afetos nas fronteiras que aceitam suborno de traficantes para facilitar a travessia das mulheres traficadas; e) Fragilidade na aplicação da lei, no sentido de que os agentes responsáveis pela aplicação da lei, não tem um domínio profundo da matéria em alusão, por falta do necessário preparo, neste caso, trata-se de policiais, procuradores e juízes, que muitas vezes absolvem esses criminosos, alegadamente por falta de prova ou por meio de corrupção protagonizada pelos traficantes a estes agentes por forma amolecer o caso em investigação.

Por sua vez, o relatório da SADC (2016), intitulado: Tráfico de pessoas na região da $S A D C$, chegou a ilação/conclusão de que as causas do tráfico de mulheres são: a instabilidade política nos países de origem, pobreza, desemprego e a falta de oportunidades de geração de rendimentos. Os outros fatores de pressão incluem a pandemia de VIH/SIDA, que tem destruído as estruturas de apoio às famílias nas comunidades, levando aos seus dependentes a vários riscos quando procuram alternativas de sobrevivência, essa busca pela sobrevivência, constitui um dos factores de pressão que conduzem ao tráfico de mulheres, para além da sua alienação em sectores da agricultura, pesca, minas e trabalho doméstico.

O fator de pressão mais comum é a procura pela indústria do sexo comercial, onde as vítimas, mormente as do sexo feminino, tanto adultas como jovens, são exploradas. Essas vítimas, são na sua maioria mulheres vulneráveis, facilmente aliciadas pelos traficantes com promessa de um emprego rentável, principalmente na África do Sul, isto porque o país tem um grande mercado de sexo a nível da SADC, pelo fato de atrair grande parte da população africana e não africana, devido as suas enormes potencialidades econômicas, tais como: maior empregabilidade, produtividade e maior facilidade na realização de transações comerciais, comparativamente com os outros países da SADC e do mundo.

A existência de um nível de industrialização elevado e uma bõa formação escolar, torna a população capacitada para uma maior produção e de melhor qualidade; e existência de mercado com alto poder econômico, pois, a África do Sul, apesar de ter sofrido os problemas do Apartheid, com disparidades econômicas, sociais e culturais astronómicas entre brancos e negros, podemos dizer que alguns extractos da população negra, têm melhores condições econômicas, comparativamente com o resto do continente africano. Isto é, com um poder de aquisição de bens e serviços relativamente elevado e boa rede de transportes. África do Sul é reconhecida como um país que tem uma excelente rede rodoviária, viária e ferroviária, não só por ligar todos os pontos do país, mas também com boas ligações com os países vizinhos, entre outros (PEREIRA, 1995), como mostra o mapa abaixo.

Conforme uma organização não governamental Save the Children (2009), em Moçambique, as mulheres de 14-25 anos de idade são transportadas dos seus locais de proveniência para África do Sul pelos membros da rede de traficantes e chegado a fronteira, são facilitados a entrada para África do Sul por indivíduos designados localmente por mareyane que as facilitam a travessia ilegal em troca de dinheiro, podendo ser a pé ou de taxis locais sob cúmplice ou sob olhar desatenta das autoridades fronteiriças.

Mapa - 1. Localização das principais rotas de tráfico de mulheres para fins sexuais em Moçambique e em África Austral no geral. 


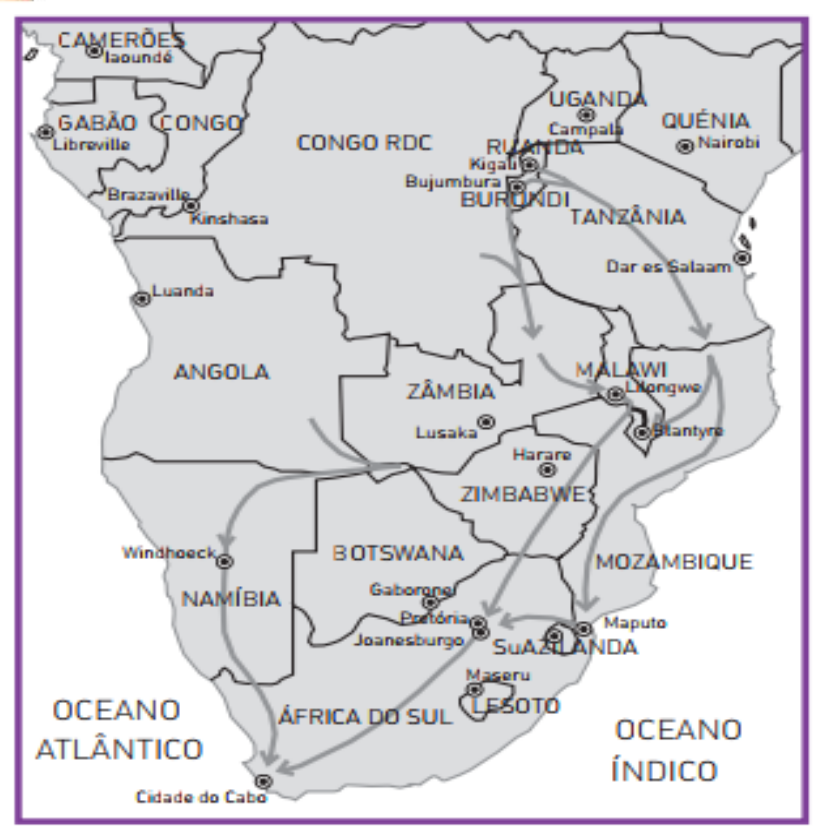

Fonte: UNESCO (2006, p.29).

De uma forma geral, o mapa da África Austral acima apresentado, mostra as principais rotas do tráfico de mulheres para fins sexuais. É possível observar a rota do tráfico de Moçambique para África do Sul, principalmente para Joanesburg em West Rand, perto de Carletonville. Segundo UNESCO (2006), existem registros sobre a existência de "paradas", onde as jovens recrutadas são exibidas a possíveis compradores prontos a pagar mais de 650 Randes (ZAR) por cada "esposa", por um lado. Por outro lado, “as esposas" sexuais podem ser encomendadas conforme a procura. Dentro deste contexto, a região da SADC possui uma elevada prevalência do VIH/ AIDS no mundo. Apesar de representar 3,5\% da população mundial, os países da SADC são responsáveis por mais de $37 \%$ da população mundial vivendo com VIH e AIDS (SADC, 2006). Mesmo com essa pandemia dizimando vidas humanas, o tráfico de mulheres para fins de exploração sexual tem sido uma realidade na região da SADC e lança-se um grande desafio para as autoridades políticas e organizações civis de todos os países membros, devido a sua nefastidade para as vítimas e para sociedade em geral. Em decorrência disso, houve, em vários países da SADC, forte deterioração do aparato policial que controla as fronteiras entre esses países membros, devido a problematica do HIV/SIDA

Em Moçambique, para controlar as rotas (origem, trânsito e destino) do tráfico de pessoas na Região da SADC, normalmente obedece aos seguintes padrões: A nível interno dos EstadosMembros: no interior dos Estados-Membros da SADC; Tráfico de pessoas intra-regional: entre os diferentes Estados-Membros da SADC; Tráfico de pessoas inter-regional: entre os Estados-Membros da SADC e países de outras regiões de África; e Tráfico de pessoas intercontinental (nível mundial): entre os Estados-Membros da SADC e países de outros continentes, tais como a Ásia e a Europa (SADC, 2016). Trata-se de uma realidade complexa porque envolve uma sofisticada e modernizada rede criminosa, cuja descoberta exige um redobrado esforço conjunto, desde às autoridades de manutenção da ordem pública durante a sua fiscalização, procuradoria na sua investigação, tribunais na responsabilização criminal dos envolvidos, população em geral, inclusive as próprias vítimas na denúncia de qualquer caso do gênero. Esta rede de traficantes, pelo alto rendimento desta atividade, transformou-se num verdadeiro crime de colarinho branco, envolvendo inclusive políticos

Steele (2013), aponta que vários fatores favoráveis ao tráfico de mulheres na Região da SADC relacionam-se com o défice existente nos sistemas legislativos, administrativos e institucionais dos Estados-Membros, tais como: a falta de legislação específica antitráfico de pessoas em alguns países ou constrangimentos na aplicação da referida legislação. Segundo HSRC (2010), a maioria dos agentes da lei e ordem da SADC ainda tem falta de capacidade adequada para identificar e investigar casos de tráfico de mulheres de forma eficaz, dificultando o devido registro de dados. As fronteiras porosas entre os 
Estados-Membros da SADC, são também considerados como outro fator que permite o tráfico de mulheres. Por exemplo: as grandes extensões de áreas de fronteiras sem patrulhamento entre os países vizinhos, permitem aos traficantes e contrabandistas transportarem vítimas de um país para outro sem custos de serem identificados pelas autoridades policiais.

No entanto, para Steele (2013), grande parte de oficiais da polícia ou de polícias de guarda fronteiras na Região da SADC, são corruptos ao facilitarem a evasão aos procedimentos legais de imigração por parte de traficantes em troca de valores monetários. Como aponta o relatório da SADC (2016), embora a tecnologia e globalização tenham criado oportunidades significativas para o controle e prevenção do tráfico de mulheres, elas criaram também oportunidades aos traficantes para recrutarem as suas vítimas de forma racional e com estratégias sofisticadas. A evolução verificada nas novas tecnologias de informação e comunicação (TIC), incluindo o acesso à internet e o uso extensivo das plataformas das redes sociais, proporcionam espaços aos traficantes para estabelecerem ligação e recrutarem suas vítimas. Steele (2013), indica que a falta de sensibilização pública sobre o tráfico de mulheres nas comunidades, bem como nas instituições responsáveis pela aplicação da lei, permite também o tráfico de mulheres na Região.

\subsection{Quadros Jurídico-legais Nacionais sobre o Tráfico de Mulheres nos Estados-Membros da SADC.}

Dos 15 Estados-Membros da SADC, apenas 13 possuem legislação específica (como mostramos na tabela abaixo), que se debruça sobre o crime do tráfico de pessoas, mormente aos aspectos estratégicos nacionais e planos de ação sobre o tráfico de pessoas, procedimentos operacionais padronizados, mecanismos de referência e directrizes para identificar vítimas do tráfico de pessoas (OBSERVATÓRIO ACP DAS MIGRAÇÕES, 2011). Mas 86,7\% dos EstadosMembros com implementação deficitária das leis continua ainda na fase embrionária, pautando pelo desenvolvimento de regulamentos de execução (SADC, 2009; 2016).

Quadro 1. Legislação nacional sobre o tráfico de mulheres em cada país da SADC

\begin{tabular}{|c|c|}
\hline País & Título das legislações nacionais \\
\hline Angola & $\begin{array}{l}\text { - Lei sobre a Criminalização das } \\
\text { Infracções subjacentes ao } \\
\text { Branqueamento de Capitais, Lei } \\
3 / 2014 \text { (Artigo } 19 \text { trata de questões } \\
\text { relativas ao tráfico de pessoas). } \\
\text { - Código Penal Provisório (Os } \\
\text { artigos } 177 .^{\circ} \text { e } 183^{\circ} \text { tratam de } \\
\text { questões relativas à escravatura, à } \\
\text { servidão e ao tráfico de pessoas). } \\
\text { Contudo, o código provisório não } \\
\text { está ainda em vigor. }\end{array}$ \\
\hline África do Sul & $\begin{array}{l}\text { - Lei } n^{0} 7 / 2013 \text {, sobre Prevenção e } \\
\text { Combate ao Tráfico de Pessoas. }\end{array}$ \\
\hline Botsw & $\begin{array}{l}\text { - A Lei } \mathrm{n}^{\mathrm{o}} 32 / 2014 \text {, sobre Anti- } \\
\text { Tráfico Humano. }\end{array}$ \\
\hline $\begin{array}{c}\text { República } \\
\text { Democrática do } \\
\text { Congo (RDC) }\end{array}$ & $\begin{array}{l}\text { - Está em curso a elaboração da } \\
\text { legislação específica sobre o tráfico } \\
\text { de pessoas }\end{array}$ \\
\hline Lesoto & $\begin{array}{l}\text { - Lei } n^{\circ} 1 / 2011 \text {, sobre Anti-Tráfico } \\
\text { de Pessoas. }\end{array}$ \\
\hline Madag & $\begin{array}{l}\text { - Lei } N^{\circ} \text { 2014-040, de } 20 \text { Janeiro } \\
2015 \text { [Lei Anti-Tráfico de Pessoas } \\
\text { No. 40, de 2014], que emenda a Lei } \\
N^{\circ} 2007-038 \text {, de } 14 \text { Janeiro de } 2008 \\
\text { [Lei Anti-Tráfico No. 38, de 2007]. }\end{array}$ \\
\hline Malawi & $\begin{array}{l}\text { - Lei } n^{0} 3 / 2015 \text {, sobre o Combate ao } \\
\text { Tráfico de Pessoas. }\end{array}$ \\
\hline Maurícias & $\begin{array}{l}\text { - Lei } n^{0} 6 / 2009 \text {, sobre o Combate ao } \\
\text { Tráfico de Pessoas. }\end{array}$ \\
\hline Moçambique & $\begin{array}{l}\text { - Lei } n^{\circ} 6 / 2008 \text {, sobre de Combate } \\
\text { ao Tráfico de Pessoas. }\end{array}$ \\
\hline Namíbia & $\begin{array}{l}\text { - Lei } \mathrm{n}^{\mathrm{o}} 1 / 2018 \text {, sobre Combate ao } \\
\text { Tráfico de Pessoas . }\end{array}$ \\
\hline Seychelles & $\begin{array}{l}\text { - Lei } n^{\circ} \text { 9/2014, sobre a Proibição do } \\
\text { Tráfico de Pessoas . }\end{array}$ \\
\hline Swazilândia & $\begin{array}{l}\text { - Lei no 7/2013, sobre a Prevenção e } \\
\text { Combate ao Tráfico de Pessoas. }\end{array}$ \\
\hline
\end{tabular}




\begin{tabular}{|c|l|}
\hline $\begin{array}{c}\text { República } \\
\text { Unida da } \\
\text { Tanzânia }\end{array}$ & $\begin{array}{l}\text { - Lei } \mathrm{n}^{\circ} 7 / 2009, \text { sobre a Proibição do } \\
\text { Tráfico e Contrabando de Pessoas . }\end{array}$ \\
\hline Zâmbia & $\begin{array}{l}\text { - Lei } \mathrm{n}^{\circ} 11 / 2008, \text { sobre Anti-Tráfico } \\
\text { Humano. }\end{array}$ \\
\hline Zimbabwe & $\begin{array}{l}\text { - Lei no 4/2014, sobre o Combate ao } \\
\text { Tráfico de Pessoas . }\end{array}$ \\
\hline
\end{tabular}

Fonte: (SADC, 2016; DEPARTAMENTO DE ESTADOS

UNIDOS, 2017).

Na região da SADC, o país que não tem uma lei específica sobre o tráfico de pessoas é a República Democrática do Congo (RDC). Moçambique, Madagáscar e Zâmbia foram os primeiros países a ter dispositivo legal de combate contra o tráfico de pessoas. Mas com a reunião dos ministros da Comunidade para o Desenvolvimento da África Austral (SADC), responsáveis pela luta contra o tráfico de pessoas, emanou-se em maio de 2009, um plano de acção estratégico de combate contra o trafico, com período de dez anos de vigência (OBSERVATÓRIO ACP DAS MIGRAÇÕES, 2011), com medidas legislativas e políticas de proteção, carregadas de compromisso entre Estados-Membros para edificar uma ampla estrutura normativa e institucional, baseada numa definição clara da noção de tráfico de pessoas, a fim de dissuadir os traficantes, o que frequentemente não acontece.

A maior parte das intervenções da região da SADC de luta contra o tráfico de mulheres, têm enfrentado dificuldades, devido aos escassos recursos financeiros para a sua operacionalização, exceto a África do Sul que depende do financiamento de doadores, tais como a União Europeia e o Gabinete do Departamento do Estado Norte-americano para a Monitorização e o Combate Contra o Tráfico de Pessoas (SADC, 2016).

\subsection{O cenário do Trafico de Mulher em Moçambique e África do Sul}

\subsubsection{Moçambique}

Gostaríamos, no entanto, de começar essa seção com uma pequena observação: no dia 30 de julho de 2017, Moçambique, recordou pela primeira vez, o dia Mundial Contra o Tráfico de Pessoas, com a realização de uma campanha de sensibilização no Distrito de Chókwè, na Província de Gaza, que é tido como lugar de frequência do tráfico de pessoas. Neste evento juntou-se estudantes, professores, dirigentes, líderes comunitários e a comunidade em geral, sob o lema "Promoção da Migração Segura, Prevenção e Combate Contra o Tráfico de Pessoas", com o fito de sensibilizar a sociedade moçambicana a compreender como o tráfico de pessoas tornou-se um problema público (PGR, 2017).

Moçambique localiza-se no sudeste do continente africano e é banhado pelo Oceano Índico a leste, fazendo fronteira com a Tanzânia aon norte; Malawi e Zâmbia a noroeste; Zimbabwe a oeste; Suazilândia e África do Sul a sudoeste. A capital e a maior cidade do país é Maputo. O país vem do confronto de duas guerras, sendo a primeira contra os portugueses (1964-1975), seguida do conflito armado (19761992) entre a Frente de libertação de Moçambique (FRELIMO) e a Resistência Nacional de Moçambique (RENAMO), que resultou em milhares de vítimas humanas, diferentemente dos outros países da SADC, exceto Angola, Cabo Verde, Guiné-Bissau, São Tomé e Príncipe, sendo Angola com um histórico muito similar de Moçambique.

A população moçambicana atualmente corresponde a 28.861 .863 habitantes, distribuída em dez províncias ${ }^{2}$, sendo 15.061.006 mulheres e

\footnotetext{
2 No Brasil denomina-se Estados.
} 
13.800.857 homens, sendo de faixa etária predominantemente jovem, conforme dados do Instituto Nacional de Estatística (INE, 2017) ${ }^{3}$ relativos aos resultados definitivos do último censo geral da população e habitação realizado em 2017.

Moçambique é um país privilegiado por se localizar ao longo da costa do oceano Índico e fazer fronteiras com vários países que dependem dos seus portos e caminhos de ferro para movimentar mercadorias e pessoas para os países de hiterland, proporcionando a existência de facilidades na realização de transações comerciais a nível da África e fazendo com que a mobilidade social seja cada vez mais acentuada, por um lado. Por outro lado, a migração para a vizinha África do Sul em busca de trabalho, principalmente nas pequenas firmas lá existentes, com destaque para salões de beleza, que constitui um dos maiores atrativos de migração de mulheres jovens ou adolescentes, principalmente da região sul do país.

O relatório da Procuradoria-Geral da República de Moçambique (PGR, 2014) mostra que na zona Sul do país, ocorre com frequência um movimento migratório legal e ilegal para a República da África do Sul (RSA). Esta prática de mobilidade é uma herança social e cultural, profundamente institucionalizada nas famílias, principalmente com a abertura das minas de ouro de Witwatersrand, em 1886, que contribui até hoje, de forma significativa, para a obtenção de empregos de muitas famílias (PGR, 2014).

As rotas usadas para transportar às vítimas de tráfico de Moçambique para a África do Sul são as seguintes: da fronteira de Ressano Garcia para Gauteng, da fronteira do Libombo para África do Sul e da fronteira de Ponta de Ouro para a África do Sul. Entre 19 de Janeiro de 2004 a 6 de Fevereiro do mesmo ano, estimou-se que cerca

\footnotetext{
${ }^{3}$ Disponível em: <http://www.ine.gov.mz/operacoesestatisticas/censos/censo-2007/censo-2017/divulgacao-os-
}

de 2.260 pessoa foram traficadas (UNESCO, 2006)

Dentro deste contexto, muitas mulheres jovens e adolescentes são atraídas para África do Sul, a procura do emprego. Esta realidade está associada a fragilidade socioeconômica do país, tornando-as vulneráveis a sedução pelos traficantes, com promessa de uma garantia de trabalho de forma rápida e fácil.

Como sabemos, o tráfico de mulheres é um processo complexo por envolver uma rede de diversos indivíduos com uma forma peculiar de atuação e com uma estrutura bem organizada e de difícil descoberta. Normalmente caracteriza-se pelas seguintes fases: recrutamento por meio de sedução, devido a sua vulnerabilidade social; solicitação do consentimento familiar como se o trabalho fosse decente, legalização dos seus documentos individuais, transporte e seu alojamento.

Um fato importante, apontado pela convenção de Palermo das Nações Unidas (2000) é de que a exploração de mulheres pode consistir em exploração para fins de prostituição ou outras formas de exploração sexual, o trabalho forçado ou similar a escravatura.

Em Moçambique, vários casos reportados são inerentes a mulheres jovens e adolescentes, ambas vulneráveis economicamente e com um nível de escolaridade baixo. Devido a sua condição social e econômica deploráveis, os traficantes aproveitam desta sua vulnerabilidade social, prometendo um emprego decente em outros países, com maior destaque para África do Sul, onde o trabalho em salões de beleza, transformou-se num emprego atrativo para a maioria das mulheres moçambicanas. A mesma rede, depois de convencer as suas vítimas, tem se encarregado pelo tratamento da documentação individual (passaporte com visto de estadia no

resultados-preliminares-iv-rgph-2017>. Acesso em 28 de março de 2018. 
estrangeiro) necessária para a travessia na fronteira e sua manutenção no estrangeiro, seu transporte e acomodação. Trata-se de uma rede de intervenientes, desde os que encomendam aqueles que executam e os que procedem o seu transporte. (MARIANO, et al, 2016).

Nesta rede de tráfico tão rentável, na visão dos autores acima, o último beneficiário desta atividade, raramente é conhecido e presume-se que seja pessoas poderosas "peixe graúdo" com fortes poderes de amolecer o poder das autoridades policiais e judiciais em caso de descoberta por meio de poderes financeiros "corrupção". O mais inquietante ainda nesta perspectiva, é que em poucas condenações existentes em África, nunca foram revelados os seus verdadeiros mandantes ou beneficiários finais. O caso elucidativo é da DIANA, uma moçambicana condenada a pena perpétua pelo Tribunal da África do Sul pelo tráfico de mulheres moçambicanas para fins de exploração sexual:

No dia 20 de julho de 2011, o tribunal de Pretoria, África do Sul, condenou uma moçambicana de nome ALDINA DOS SANTOS (DIANA), de 32 anos de idade, a uma pena de prisão perpétua, em virtude desta ter praticado tráfico (de Moçambique para África do Sul) de 3 menores de idade para fins de exploração sexual. A juíza do caso, disse durante a leitura da sentença que os interesses da ré nunca devem se sobrepor aos das vítimas, dos Estados moçambicano e África do Sul e muito menos da organização mundial contra o tráfico de pessoas. Ainda a juíza disse que a pena perpétua aplicada a ré se deveu a falta de arrependimento pelo que fez, defendendose sempre que " as vítimas se mostraram dispostas a serem exploradas sexualmente, daí que as levou para África do Sul". Conforme a juíza, a ré para além de ter explorado as jovens sexualmente, obrigava-as a tomar estimulantes (drogas) para que elas aguentassem com a sobrecarga de manter

\footnotetext{
${ }^{4}$ Disponível em:

<http://www.verdade.co.mz/nacional/21026-justi-ca-sul-
}

relações sexuais com mais de dez (10) parceiros por dia. (JORNAL VERDADE,2011, online) ${ }^{4}$.

Este caso, é um dos mais mediatizados, o que levou o jornalista Hélio Filimone, a escrever o seu livro, intitulado: “Caso Diana e o tráfico de pessoas em Moçambique" (2017). Este caso foi denunciado em 2011, por um canal público sulafricano, no qual apontava existir em Moçambique uma rede de traficantes que operava, desde o recrutamento até às casas de prostituição na África do Sul (SERRA, s/d). Os dados extraídos do trabalho de campo, apontam ainda existirem casos de tráficos de mulheres que continuam no anonimato, por um lado, devido ao alto secretismo desta atividade que torna difícil a sua descoberta. Por outro lado, as suas vítimas não conseguem ter a coragem de denunciar tais práticas por temer alguma vingança trágica por parte dos criminosos, quer contra elas próprias, quer para seus familiares, tendo em conta que o sistema de administração da justiça não é eficiente e eficaz quanto a proteção das denunciantes, tanto como para o enfrentamento deste fenômeno criminal.

A demais, na passagem pelas fronteiras tem -se notado outra fragilidade inerente ao movimento desusado de pessoas, vezes sem conta confundem-se com os movimentos migratórios regulares, sendo por isso tão difícil discernir as vítimas deste tráfico entre os diferentes movimentos migratórios, por um lado. Por outro lado, a corrupção promovida pelas autoridades fronteiriças permite a fraca fiscalização dos migrantes (UNESCO, 2006).

O tráfico é uma forma de poder paralelo que os indivíduos criminosos usam, tendo em conta a vulnerabilidade social e econômica das vítimas. Neste processo, utilizando as palavras de Marx (2013), podemos afirmar que consiste em controlar e explorar o esforço das vítimas, recebendo avultadas somas em dinheiro e em

africana-condena-diana-a-prisao-perpetua>. Acesso em: 04 de agosto de 2017 
contrapartida as vítimas recebem uma quantia irrisória e outros benefícios que não compensa o esforço por elas empreendido. Neste caso vertente, as vítimas enquanto nas mãos dos traficantes, perdem por completo os seus direitos à liberdade, ficando na total dependência dos traficantes (MONTEIRO \& OSORIO, 2009).

O tráfico de mulheres para fins de exploração sexual na SADC no geral, e em Moçambique e em Angola em particular, tem sido motivado pela ideia de vida fácil por parte da rede de tráfico, por um lado. Por outro lado, pela exclusão socioeconômica de muitas famílias nestes países, os indivíduos tornam-se propensos a aceitar qualquer proposta de emprego sem questionamento, embora poucas vezes as vítimas por si só se envolvem em exploração sexual por consentimento próprio, como fonte de sobrevivência por si encontrada.

Estes casos pela sua complexidade na investigação, o seu desfecho tem sido caraterizado por uma morosidade e muitas vezes caracteriza-se pela impunidade dos seus autores pela falta da necessária colaboração das vítimas, por elas acharem uma via legal para a sua sobrevivência, ignorando totalmente a lei e arriscando-se a vida. Por outro lado, pela falta de provas evidentes, uma vez que ninguém se prontifica a apresentar provas indiciárias do fato.

Em muitas cidades do mundo, em especial nas cidades moçambicanas, angolanas, sul africanas, malawianas, zambianas, tanzanianas, congolesas, etc., o tráfico de mulheres para fins de exploração sexual tem ocorrido também a nível interno, em prostíbulos e em bares, em que um determinado traficante, recruta e seleciona várias mulheres e coloca-as num prostíbulo, onde o valor cobrado por cada programa "atividade sexual", vai ao traficante e este, entrega as traficadas, no final de cada mês, um valor mensal simbólico, mediante o rendimento de cada uma delas. Pelo nível alto de analfabetismo e sob efeito de bebidas alcoólicas e outras drogas que consomem como estimulantes sexuais, algumas se arriscam a fazer sexo desprotegido, tornando-se assim propensas a contaminação pelas doenças de transmissão sexual incluindo HIV-AIDS.

Moçambique assinou em 2003 e aderiu a convenção das Nações Unidas contra o crime organizado transnacional relativo a prevenção, repressão e punição de tráfico de pessoas, em especial Mulheres e Crianças, a conhecida como protocolo de Palermo. Embora tenha aderido este protocolo, a sua aplicabilidade ainda é muito deficitária devido à falta de recursos humanos qualificados e especializados nesta matéria, referindo-se a juízes, procuradores inclusive policiais.

No mesmo país, a prostituição autônoma não constitui crime, mas a sua exploração e o tráfico de mulheres para fins de exploração sexual, é punido pela lei no 35/2014 de dezembro de 2014, que atualiza o código penal moçambicano, no seu artigo 198 sobre tráfico de pessoas, preconizando que:

Aquele que recrutar, transportar, acolher, fornecer ou receber uma pessoa, sob pretexto de emprego, formação, aprendizagem, para fins de prostituição, trabalho forçado, escravatura, servidão involuntária, por dívida será punido com pena de prisão maior de 16 a 20 anos. (Código penal moçambicano, 2014, art.198) ${ }^{5}$.

Embora a lei moçambicana prevê penas pesadas para os traficantes, mas a realidade concreta mostra fragilidade na sua aplicação, caracterizando se por impunidades ou aplicação de penas brandas aos seus autores, alegadamente por falta de provas indiciárias suficientes, daí que os traficantes se sentem encorajados em dar continuidade a prática deste crime.

35_2014Codigo_Penal.pdf>. Acesso em: 04 de agosto de 2017. 
1.3.2 África do Sul

Na região da SADC, o tráfico inter-regional de pessoas, incluindo crianças, processa-se com origens e destinos comuns em quase todos os países. A África do Sul figura entre os principais países de destino dos casos de tráfico de pessoas provenientes da região e de países da África Subsariana, mas também de outras origens como Tailândia, China, Brasil e países da Europa (OBSERVATÓRIO O ACP DAS MIGRAÇÕES, 2011).

África do Sul é um país meridional, privilegiado por se localizar nas duas costas dos oceanos que banham o continente africano (Atlantico - a este e Índico - a leste), ocupando a maior parte da extremidade sul. A paisagem é variada, com uma população de 54.2 milhões de habitantes. As suas maiores cidades são: Joanesburgo (cidade comercial), cidade do Cabo (cidade administrativa), Pretória (cidade Legislativa) e Bloemfontein (cidade Judiciário) (OTAVIO, 2003). Dentre estas cidades, a de Cabo e Johannesburgo são as principais que promovem maior concentração populacional, devido a localização das indústrias, abrigando empresas da área metalúrgica, petroquímica e setores de produção de veículos, locomotivas, alimentar, entre outros (VISENTINI, 2010).

A economia sul-africana é muito diversificada, partindo desde à prestação de serviços, indústria, além dos setores primários, como o extrativismo mineral e a produção agropecuária. Outra fonte de receita é a atividade turística, desenvolvida na Savana, conhecida como safári, que atrai milhões de turista de todo o mundo, além do turismo urbano, especialmente na cidade do Cabo e Joanesburgo (SOUTH ÁFRICA BUSINESS GUIDEBOOK, 2005).

O setor industrial é bastante diversificado, entretanto, isso não evita problemas tais como: desigualdade social, elevado índice de desemprego, marginalidade, entre outros
(RODRIK, 2006). Dentro deste contexto, a África do Sul é muito vulnerável com cerca de $71 \%$ ao tráfico de pessoas à escala regional (OBSERVATÓRIO O ACP DAS MIGRAÇÕES, 2011). È um centro privilegiado pelas redes internacionais de prostituição, traficando mulheres estrangeiras. O mesmo país, tem o maior número de soropositivos do mundo, cerca de 5,7 milhões de pessoas. De acordo com os dados recentes, tornados públicos pelo Observatório O ACP das migrações, a África do Sul tem $45 \%$ das prostitutas com AIDS.

Em síntese: a África do Sul é o país do continente africano com mais turistas sexuais, destino de mulheres e adolescentes a serem introduzidas no mundo da prostituição, sendo a maioria delas, proveniente do Quênia, Letônia, Malawí, Moçambique, Nigéria, Senegal, Taiwan, Tailândia, Romênia e Zâmbia (AGÊNZIA FIDES, 2004; VAN DER WAT, 2018). As redes mafiosas são as maiores protagonistas da exploração da prostituição na África do Sul, movimentando um valor aproximado a 19 bilhões de dólares, principalmente a máfia chinesa, búlgara, russa e nigeriana (VAN DER WAT; VAN DER WESTHUIZEN, 2017; ALLAIN, 2006; GOULD.; FICK, 2008; FRANKEL, 2016).

Conforme Chimumia e Wikison (2013), o drama do tráfico de mulheres tem mil aspectos na África do Sul. Para além do tráfico organizado, existem ainda tantas mulheres jovens provenientes dos países vizinhos que dedicam se a prostituição autônoma a nível dos seus bairros residenciais deploráveis, como forma por elas encontrada para a sua sobrevivência.

\section{CONCLUSÃO}

A vulnerabilidade do tráfico de pessoas nos países membros da SADC, incide sobre jovens que sentem no seu cotidiano a exclusão social e econômica, nomeadamente a pobreza, o desemprego ou falta de oportunidades de geração de rendimentos. 
Não obstante a presença de um conjunto de dispositivos legais, a sua aplicabilidade na região da SADC está aquém das expectativas do legislador, devido a vários fatores, dentre eles: a falta de preparação dos agentes responsáveis pela aplicação destes dispositivos legais; dificuldade na produção de provas indiciárias, dado que as provas incidem sobre as vítimas que raramente mostram abertura em colaborar com a justiça, por um lado. Por outro lado, tem se a corrupção dos funcionários públicos responsáveis pela aplicação da lei, desde os policiais, juízes, procuradores, entre outros funcionários afetos nas fronteiras, que recebem suborno dos traficantes, facilitando desta feita a impunidade e a travessia das vítimas de tráfico para além fronteira. 


\section{REFERÊNCIAS}

AGENZIA FIDES. África/África do sul $25 \%$ das prostitutas de Cidade de Cabo são crianças. Quinta, 24 junho de $2004 . \quad$ Disponível: <http://www.fides.org/pt/news/2387AFRICA_AFRICA_DO_SUL_25_das_prostitutas_de_Cidade_d o_Cabo_sao_criancas_Aqui_se_concentra_o_turismo_sexual_da_Africa_austral_O>. Acesso em: 25 set. 2018.

ALIANÇA Global Contra Tráfico de Mulheres (GAATW). Direitos Humanos e Tráfico de pessoas: um manual. Rio de Janeiro: GAATW,2006.

ALLAIS, Carol. Presented at the Joint Area Centers Annual Symposium: Criminal Trafficking and Slavery: the dark side of global and regional migration. Champaign, Illinois, p. 23-25, fev. 2006.

CHICHAVA, Jóse. As vantagens e desvantagens competitivas de Moçambique na integração econômica regional. Maputo, 2007.

CHIUMIA, S.; \& WILKINSON, K. 2013. Africa Check: Human trafficking - sensationalist and unsubstantiated reporting. Daily Maverick, 21 de outubro de 2013. Disponível em: $<\mathrm{http}$ //africacheck.org/reports/are-30000-kids-trafficked-intosouth-africas-sex-trade-every-year-theclaim-exaggerates-the-problem/>. Acesso em: 21 set. 2018.

COMUNIDADE de Desenvolvimento da África Austral (SADC). Human Trafficking Communique. 18 de junho de 2009. Disponível em: <http://www.sadc.int/index/browse/page/531>. Acesso em: 20 ago. 2018.

DEPARTAMENTO de Estados Unidos. Relatório sobre Tráfico de Pessoas na República Democrática do Congo. 2017. Disponível em: <http:/www.refworld.org/docid/5959ece911.html>. Acesso em: 27 ago 2018.

FRANKEL, P. Long walk to nowhere: Human trafficking in post-Mandela South Africa. New Brunswick: Transaction Press, 2016.

GLOBO. África do Sul dobra alerta sobre tráfico de seres humanos durante a Copa. Disponível em: $<\mathrm{http}$ //g1.globo.com/especiais/africa-do-sul-2010/noticia/2010/06/africa-do-sul-dobra-alerta-sobretrafico-de-seres-humanos-durante-copa.html>. Acesso em: 25 set. 2018.

GOULD, C, \& FICK, N. Selling sex in Cape Town: Sex work and human trafficking in a South African city. Pretoria: Institute for Security Studies. 2008 .Disponível em: <https://www.issafrica.org/uploads/Book2008SellingSexInCT.pdf>. Acesso em: 25 set. 2018.

INSTITUTO Nacional de Estatística. Projeções anuais da População total urbana e rural, Maputo (2007-2040). Maputo: Editora do INE, 2010.

FILIMONE, Hélio. Caso diana e o tráfico de pessoas em Moçambique. Maputo: Alcance Editores, 2017. 
JOARNAL PAÍS. Moçambique é um dos países de origem de tráfico de seres humanos no mundo. 2010. Disponível em: <http://opais.sapo.mz/index.php/sociedade/45-sociedade/6995-mocambique-eum-dos-paises-de-origem-de-trafico-de-seres-humanos-no-mundo.html >. Acesso em: 05 ago. 2017.

JORNAL Verdade. Justiça Sul-africana Condena Diana a prisão perpetua. Maputo, 21 julho de 2011. Disponível em: <http://www.verdade.co.mz/nacional/21026-justi-ca-sul-africana-condena-diana-aprisao-perpetua>. Acesso em: 04 ago. 2017.

LEI n ${ }^{\circ}$ 35/2014. Revisão do Código Penal moçambicano, de 31 de dezembro de 2014. Disponível em: <http://www.wlsa.org.mz/wp-content/uploads/2014/11/Lei-35_2014Codigo_Penal.pdf >. Acesso em: 04 ago. 2017.

MARIANO, Esmeralda; BRAGA, Carla; MOREIRA, André. Estudo sobre o tráfico de órgãos e partes do corpo Humano na Região Sul de Moçambique. Maputo: CEMIRDE, 2016.

MARX, Karl. O capital. Crítica da Economia Política. Boitempo, 2013. .Disponível em: <https://coletivocontracorrente.files.wordpress.com/2013/10/tmpsq7jbv.pdf>. Acesso em: 03 ago. 2017.

MONTEIRO, C; OSORIO, C. Tráfico de Mulheres e Criança. Maputo: WLSA Mozambique, 2009.

MURAPA, Rukudzo. Southern Africa Development Community (SADC): towards political and economic integration. 2002.

OBSERVATÓRIO ACP das Migrações. Um fenómeno mundial de sinais invisíveis: O tráfico de seres humanos na África Subsariana, Caraíbas e Pacífico. Bruxelas: 2011.

OTAVIO, Anselmo. A África do Sul Pós-Apartheid: a inserção continental como prioridade na nova geopolítica mundial. Dissertação mestrado, UFRGS, FCE, Estudos Estratégicos Internacionais, Porto Alegre, 2013.

ORGANIZACAO Internacional para Migração. Guia de Estudos - 2011. Disponível em: <https://pt.slideshare.net/profjanaina/oim-organizao-internacional-para-migracao>. Acesso em: 05 ago. 2017.

RODRIK, Dani. Understanding South African's Economic Puzzles. John F. Kennedy School of Government, set. 2006. Disponível em: <http://www.adelinotorres.com>. Acesso em: 20 fev. 2017.

PEREIRA, Analúcia Danilevicz; VISENTINI, Paulo G. Fagundes. África do Sul: História, Estado e Sociedade. Brasília. FUNAG/CESUL, 2010.

PROCURADORIA-GERAL DA REPÚBLICA DE MOÇAMBIQUE. Tráfico de pessoas em Moçambique, em particular, de criança. Maputo: Instituto Superior de Relações Internacionais, 2014.

PROCURADORIA-GERAL DA REPÚBLICA DE MOÇAMBIQUE. Informação anual de 2017 do Procurador Geral da República à Assembleia da República. Maputo: Académica, Lda, 2017.

PROTOCOLO de Palermo, 2000. Disponível em: <http://sinus.org.br/2014/wpcontent/uploads/2013/11/OIT-Protocolo-de-Palermo.pdf>. Acesso em: 05 ago. 2017. 
SADC. Política da SADC para o d o desenvolvimento, planeamento e monitorização de estratégias. Gabarone: SADC, 2012.

SADC. Política. Quadro de desenvolvimento industrial da SADC. Gabarone: SADC, 2013.

SADC. Tráfico de pessoas na região da SADC. Folheto informativo. Gabarone: SADC, 2016.

SAVE the Children. The Internal Trafficking and Exploitation of Women and Children in Mozambique. Save the Children. Mozambique: 2009.

SERRA, Carlos. Tráficos de pessoas em Moçambique da retórica das palavras à dinâmica da ação. Maputo: Fundação para Desenvolvimento da Comunidade (FDC), [s.d].

SHELLEY, Louise. Human Trafficking. A Global Perspective. New York: Cambridge University Press, 2010. Disponível em: <http:// www.globality-gmu.net/archives/3271>. Acesso em: 05 ago. 2017.

SOUTH Africa Business Guidebook 2005/2006. $10^{a}$ Norwood: 3S Special Editions Ltd. South Africa: The Department of Trade and Industry of South Africa, 2005.

SOUTH African Law Reform Commission. Project 131. Trafficking in Persons Report. Pretoria: 2008.

UNESCO. Tráfico de Pessoas em Moçambique: Causas principais e Recomendações. Policy Paper No 14.1[P], 2006.Disponível em: <http://unesdoc.unesco.org/images/0014/001478/147846por.pdf>. Acesso em: 05 ago. 2017.

UNICEF. Trafficking in human beings, especially women and children, in Africa. 2a ed. Estados Unidos: United Nations Children's Fund, 2005. Disponível em: <https://www.unicefirc.org/publications/pdf/trafficking-gb2ed-2005.pdf>.

UNICEF. Innocenti Research Centre. Italia: United Nations Children, 2005.

VAN DER WATT, M. Investigating human trafficking for sexual exploitation: From "lived experiences" towards a complex-systems understanding. University of South Africa: Ph.D, thesis under examination. 2018.

VAN DER WATT, M.; VAN DER WESTHUIZEN, A. (Re) configuring the criminal justice response to human trafficking: a complex systems perspective. Police Practice and Research, v. 18, n. 3, p. 218$229,2017$.

Recebido em: $12 / 06 / 2018$ Aceito em: 01/09/2018 

outros países da SADC

Revista da Faculdade de Direito da UFRGS, Porto Alegre, n. 39, vol. esp., p. 112-128, dez. 2018.

ISSN: 0104-6594 Site http://seer.ufrgs.br/revfacdir Email: revistafacdir@ufrgs.br 